\title{
Correction to: Modified fractional-order model for biomass degradation in an up-flow anaerobic sludge blanket reactor at Zenein Wastewater Treatment Plant
}

\author{
Mostafa M. El-Seddik ${ }^{1}$ Mona M. Galal ${ }^{2}$ - Ehab H. Rozaik ${ }^{2}$ - Ahmed G. Radwan ${ }^{3,4}$
}

Published online: 3 March 2022

๑) Springer-Verlag GmbH Germany, part of Springer Nature 2022

\section{Correction to: Environmental Science and Pollution Research} https://doi.org/10.1007/s11356-022-18797-9

The $6^{\text {th }}$ Nomenclature should be $C_{X i n}, C_{S i n}$.

The Original article has been corrected.

Publisher's note Springer Nature remains neutral with regard to jurisdictional claims in published maps and institutional affiliations.

The original article can be found online at https://doi.org/10.1007/ s11356-022-18797-9.

Mostafa M. El-Seddik

mostafaelseddek@yahoo.com

1 Sanitary and Environmental Engineering, Civil Engineering Department, Institute of Aviation Engineering \&

Technology, PhD, Giza 12815, Egypt

2 Sanitary and Environmental Engineering, Public Works

Department, Faculty of Engineering, Cairo University, PhD,

Cairo 12613, Egypt

3 Engineering Mathematics Department, Faculty of Engineering, Cairo University, PhD, Cairo 12613, Egypt

4 NISC Research Center, Nile University, Giza 12588, Egypt 